\title{
Paulo Freire: narrador e pensador ${ }^{1}$ Paulo Freire: narrator and thinker
}

https://doi.org/10.34112/2317-0972a2021V39n83p55-62

Jỗo WANderley Geraldi

O conselho tecido na substância viva da existência tem um nome: sabedoria. $A$ arte de narrar está definhando porque a sabedoria - o lado épico da verdade está em extinção. Walter Benjamin

Todos aqueles que tiveram a oportunidade de conviver ou mesmo de ouvir Paulo Freire reencontraram nas suas exposições um narrador, gostoso de ouvir, que se voltava para suas experiências e delas extraía as considerações que ia tecendo com invento e limpidez, cativantes. Seguramente perdemos, com Paulo Freire, um certo modo de inventar-se como intelectual apaixonado pelas ideias que defende, comprometido com a construção de uma sociedade mais justa e sem qualquer vergonha por assumir opções políticas.

É este Paulo Freire narrador, pensador e político que pretendo recuperar neste esboço de estudo que, seguindo seu próprio modo de expor-se, parte de uma experiência de trabalho conjunto. Por dois semestres compartilhamos os "Colóquios

1. Texto publicado como Depoimento na Leitura: Teoria \& Prática, Campinas, São Paulo, v. 16, n. 30, p. 14-19, 1997. Mantivemos parcialmente as escolhas de referência e de citação do autor.

2. Universidade Estadual de Campinas, Campinas, SP. 
Interdisciplinares em Educação" - disciplina dos cursos de pós-graduação em Educação da Unicamp, coordenados pelo educador, por Adriano Nogueira e por mim.

No primeiro semestre deste trabalho, que coincidiu com o início de seu mandato como Secretário de Educação do município de São Paulo, o objetivo foi ir discutindo às terças-feiras o que ia acontecendo no novo trabalho de Secretário, desafio que expunha na esfera da atuação pública um nome e uma trajetória. Tratava-se, então, de não perder o espaço de distanciamento que a academia proporciona, sem deixar de trazer para dentro da sala, compartilhando com alunos e colegas, os acontecimentos de uma gestão à medida que ela ia se desenvolvendo.

Nossa grande dificuldade neste semestre não foi extrair temas do cotidiano, foi selecioná-los e delimitar as preocupações num momento em que todos nós apostávamos nas possibilidades abertas pelo exercício de um mandato executivo na maior cidade brasileira. Eram inúmeros os profissionais da educação que estavam "dando uma força" para que as coisas acontecessem e dessem certo. Os problemas trazidos para as discussões eram "os nossos problemas": como expor uma perspectiva educacional, elaborando propostas que respondessem ao imediato, sabendo de antemão que algumas coisas não aconteceriam, sem deixar que este não acontecer se transformasse numa recusa da perspectiva mais ampla defendida? Tratava-se de coadunar sonhos infinitos, limitados a meios finitos e a tempo fixado.

Circulamos por vários assuntos, desde aqueles das relações políticas e partidárias até aqueles menores dos entraves burocráticos, quando a urgência das prioridades esbarra nas portarias e decretos. As portarias não eram/são portas de acesso para aqueles que queríamos ver privilegiados, muito menos ainda para as ideias que pretendíamos ver discutidas. As portarias foram e são entraves: lugares de passagem, controlam entradas e saídas. ${ }^{3}$ Mas sempre há como escapar por entre as frinchas. De memória, retomo um acontecimento. Na gestão anterior, os pãezinhos distribuídos na "merenda escolar" eram adquiridos de uma única padaria - que seguramente preencherá todos os requisitos portariais e decretariais. Com o tamanho da cidade, é fácil imaginar as distâncias que separam as escolas dessa padaria única: os pães eram cozidos num dia, levados às escolas num segundo dia e consumidos num terceiro. Pão sempre tresnoitado e duro. Vencido o contrato de fornecimento, a Prefeitura organiza uma forma de licitação de modo que aproximadamente 600

3. Fatos, temas e discussões estão no livro de Paulo Freire Trabalho, Comentário, Reflexão (1990). 
padarias passam a fornecer pães para as escolas, segundo a proximidade de localização escola/padaria (do bairro). Pão fresco todo dia.

Pretendendo repercussão na imprensa por uma decisão óbvia - em função da menor distância para a entrega, o preço diminuiu e com os recursos economizados pôde-se melhorar a merenda como um todo - a assinatura dos contratos de fornecimentos foi fixada para a mesma data. Foram 600 padarias ao Ibirapuera e nenhuma linha na grande imprensa. Como "furar" o cerco do silêncio burguês? De fato, era/é necessário furá-lo? Como construir, com uma população outra, meios de comunicação constante, sabendo que, de um outro lugar, uma outra voz, forte e arrogante, estava sempre disposta a continuar a defender os interesses que sempre defendeu?

No segundo semestre, as discussões se distanciaram do cotidiano da Secretaria, para delas se aproximarem através da leitura e estudo da obra do próprio Paulo Freire. Entre outras afirmações que circularam no período anterior, havia uma que preocupou: "como educador, Paulo Freire era o nome mais citado no país, mas também era o menos lido". A organização do trabalho passou por uma seleção prévia do autor, que escolheu, como suas [então] principais obras, os seguintes trabalhos: Educação e Atualidade Brasileira [tese de concurso público para a cadeira de História e Filosofia da Educação, a que se submeteu em Recife no ano de 1959]; Pedagogia do Oprimido [obra-prima do autor, manuscrita em 1968 e publicada em 1970 simultaneamente em inglês, espanhol e português]; Ação Cultural para a Liberdade $e$ Outros Escritos [coletânea de textos que tematizam a alfabetização de adultos, os camponeses e seus textos de leitura, a ação cultural e a conscientização]; Cartas à Guiné-Bissau [cartas dirigidas a Mário Cabral e às equipes de trabalho, antecedidas por estudo introdutório em que se tematizam "os problemas que uma sociedade revolucionária deve-se pôr no campo da educação enquanto ato de conhecimento"]; A importância do ato de ler [três artigos, o primeiro é sua conferência de abertura do $3^{\circ}$ COLE, atualmente disponível em edição mais próxima da fala do livro Leituras no Brasil, o segundo correlacionado à alfabetização de adultos e às bibliotecas públicas e o terceiro retornando à África, com a alfabetização em São Tomé e Príncipe].

A metodologia de aula que utilizamos foi a leitura prévia do texto selecionado, um encontro prévio em que elaborávamos uma leitura do texto e organizávamos um conjunto de perguntas que remetiam a uma espécie de "arqueologia" do processo de produção da obra e um terceiro encontro, este com Paulo Freire, em que nos respondia a perguntas e críticas, seguramente algumas delas impertinentes [de memória, lembro as críticas à ideologia do desenvolvimento assumida na tese 
de concurso e à visão fenomenológica presente em várias pesagens desta mesma tese e de Pedagogia do Oprimido].

Obviamente, não cumprimos o programa. ${ }^{4}$ Tomamos chimarrão em cuia trazida por Adriano Nogueira. E ficamos no estudo de Educação e Atualidade Brasileira e Pedagogia do Oprimido. Nossas muitas perguntas e algumas críticas levavam o autor ao tempo da produção, e com os olhos do fim dos anos 8 o recordava suas leituras, seus interlocutores e suas experiências, todas vinculadas à obra que estávamos estudando. Nestes encontros, muitas vezes Paulo Freire se referiu a um necessário reencontro seu com a Pedagogia do Oprimido, que ele vinha preparando e que é publicado na forma de livro em Pedagogia da Esperança em 1992.

É deste trabalho compartilhado que retiro uma hipótese de leitura da obra de Paulo Freire e que apresento como um ponto de vista, a ser melhor especificado numa necessária retomada de sua obra completa. Paulo Freire foi um narrador que retirou da experiência a reflexão teórica que nos apresenta como conselhos.

Walter Benjamin (1985), no estudo sobre o narrador, afirma:

São cada vez mais raras as pessoas que sabem narrar devidamente. Quando se pede num grupo que alguém narre alguma coisa, o embaraço se generaliza. É como se estivéssemos privados de uma faculdade que nos parecia segura e inalienável: a faculdade de intercambiar experiências.

Uma das causas desse fenômeno é óbvia: as ações da experiência estão em baixa, e tudo indica que continuarão caindo até que seu valor desapareça de todo. (BENJAMIN, 1985, p. 197-198).

Acompanhando o texto de Walter Benjamin, vamos encontrando alguns elementos que poderiam dar corpo à hipótese de leitura de Paulo Freire, complementando-a com outras perguntas a responder em estudo futuro:

a. o narrador camponês e o narrador marinheiro: como "a experiência que passa de pessoa a pessoa é a fonte a que recorreram todos os narradores”, estes são

4. Pior do que não termos cumprido o programa de trabalho proposto foi minha exigência de que os encontros com Paulo Freire não fossem gravados, para que não caíssemos na tentação a que sucumbimos os três: ao mesmo tempo preparávamos a publicação das discussões do semestre de trabalho anterior e eu não via naquele momento urgência alguma para o registro de "arqueologia" que pretendíamos fazer. 
divididos em dois grupos que se interpenetram - "quem viaja tem muito o que contar"s, e quem fica conhece as histórias e tradições de seu país. $\mathrm{O}$ marinheiro e o camponês. $\mathrm{O}$ camponês e o marinheiro. Paulo Freire poderia ter sido ambos? Suas obras remetem sempre à experiência do SESI e, posteriormente, a Angicos. O exílio o torna marinheiro e a experiência com a África inclui entre suas reflexões o corpo, seu gingado e sua dança;

b. o conselho: na narrativa tem uma dimensão prática e utilitária. "Essa utilidade pode consistir seja num ensinamento moral, seja numa sugestão prática, seja num provérbio ou numa norma de vida - de qualquer maneira, "o narrador é um homem que sabe dar conselhos. [...] Aconselhar é menos responder a uma pergunta que fazer uma sugestão sobre a continuação de uma história que está sendo narrada"6. Retiro um exemplo de Paulo Freire - depois de narrar sua relação de dor com a chuva, lama ou barro pegajoso, desvelando a razão de ser de sua experiência de sofrimento para dele libertar-se, aconselha: “[...] alcançar a compreensão mais crítica da situação de opressão não liberta ainda os oprimidos. Ao desvelá-la, contudo, dão um passo para superá-la desde que se engajem na luta política pela transformação das condições concretas em que se dá a opressão. O que quero dizer é o seguinte: enquanto no meu caso foi suficiente conhecer a trama em que meu sofrimento se gestava para sepultá-lo, no domínio das estruturas socioeconômicas, a percepção crítica da trama, apesar de indispensável, não basta para mudar os dados do problema. Como não basta ao operário ter na cabeça a ideia do objeto que quer produzir. É preciso fazê-lo.” 7 A história da mudança é uma história ainda a construir. Se o conselho não responde a uma pergunta, mas sugere uma continuação para a história, é este fim da história que não está fixado no pensamento de Paulo Freire, porque atingida a não opressão, outra história começa nesta eterna busca do "fazer-se homem". Os conselhos, que demandam a sabedoria, que como lado épico da verdade demanda compromissos, sonhos e utopias, são tecidos de "saber de experiência feito" para construir o "inédito viável";

5. BENJAMIN, 1985, p. 198.

6. BENJAMIN, 1985 , p. 200.

7. FREIRE, 1992, p. 32.

8. Cf. FREIRE, 1992, p. 189-191. 
c. a liberdade de interpretação e a atemporalidade da narrativa: exigindo uma comunidade de ouvintes [a oralidade de Paulo Freire não se encontra apenas em suas palestras, aulas e entrevistas, mas também em seus livros, mesmo naqueles a que não chamou de "livros falados" "], na narrativa contém informações plausíveis, retomadas no eterno re-contar a história que se tece na rede das interpretações distintas e nos diferentes desempenhos de cada narrador, e destes em cada situação. "Contar histórias sempre foi a arte de contá-las de novo [...]" ${ }^{10}$. Em Paulo Freire, observemos a frequência com que reconta a experiência do SESI (por exemplo, em Educação como prática da liberdade e em Pedagogia da Esperança), retorna-se a Angicos, volta-se a Recife e à casa paterna. A cada novo tempo, a narrativa narrada retorna, reinterpretada e fundamentando conselhos novos, porque dialogam múltiplos passados com o presente olhado com o desejo de futuro;

d. A preferência pelo fluir da vida às explicações conectadas entre causas e efeitos: no narrador, os desígnios do futuro, as reminiscências do passado, o sentido da vida, a autoridade da experiência vivida, o curso das coisas sobrepõem-se à tentativa de encontrar explicações lógicas, coerentes e coesas, porque se assume que as vidas dos homens e das mulheres são prenhes de saberes e desejos. Talvez nestas "operações" próprias à narrativa possam ser encontrados indícios de explicação para um processo de produção que me parece uma constante em Paulo Freire: todo ciclo de reflexão teórica, em que os pensamentos se organizam em obra, vem precedido de um ciclo de experiências multifacetadas, de modo que a obra final condensa em um gesto pontos diversos de uma trajetória prévia. Pedagogia do Oprimido, por exemplo, é antecedida por obras que remetem à experiência no SESI (Educação e atualidade brasileira, depois com retoques, Educação como prática da liberdade, mas também por um texto a propósito da gestão de João Alfredo Gonçalves da Costa Lima como Reitor da Universidade de Recife, pelos livros e cadernos de exercícios de alfabetização e pelo livro Alfabetização e Conscientização. Em resumo, a obra-prima de Paulo Freire condensa a experiência brasileira pré-golpe militar de $1964 \mathrm{e}$ as primeiras experiências no exílio, especialmente o trabalho realizado junto

9. Circulam entre nós inúmeros vídeos, verdadeiras aulas de Paulo Freire. Mas também circulam livros, chamados por ele de "livros falados", que são transcrições e edições de entrevistas e debates. Exemplo típico é Paulo Freire ao vivo, organizado por Aldo Vannucchi, com a participação de Wlademir dos Santos, Edições Loyola, 1983. 10. BENJAMIN, 1985, p. 205. 
aos camponeses chilenos de que Extensão o Comunicação? Possivelmente seja a obra mais conhecida entre nós);

e. a subjetividade na narrativa: segundo Walter Benjamin, "a narrativa [...] é ela própria, num certo sentido, uma forma artesanal de comunicação. Ela não está interessada em transmitir o "puro em-si" da coisa narrada como uma informação ou um relatório. Ela mergulha a coisa na vida do narrador para em seguida retirá-la dele. Assim se imprime na narrativa a marca do narrador, como a mão do oleiro na argila do vaso" ${ }^{{ }_{11}}$. No modo paulo-freireano de falar, corpo, gesto e voz se unem na forma estética de defender a ética. São conhecidos seus neologismos, que, ao contrário do rebuscado modo acadêmico de se expor, são de fácil compreensão, parecem dizer precisamente aquilo que devem dizer.

Nunca um acontecimento, um fato, um feito, um gesto de raiva ou de amor, um poema, uma tela, uma canção, um livro têm por trás de si uma única razão. Um acontecimento, um fato, um feito, uma canção, um gesto, um poema, um livro se acham sempre envolvidos em densas tramas, tocados por múltiplas razões de ser que de algumas estão mais próximas do ocorrido ou do criado, de que outras são mais visíveis enquanto razão de ser. Por isso é que a mim me interessou sempre muito mais a compreensão do processo em que e como as coisas se dão do que o produto em si. (FREIRE, 1992, p. 18).

Paulo Freire, como narrador, soube extrair da experiência seus conselhos, e seguindo seus próprios conselhos construiu uma teoria pedagógica, dela extraiu uma metodologia de trabalho e com todos compartilhou seus achados. Legou-nos uma obra. Para aqueles que querem ultrapassar o comentário, deixou-nos um exemplo.

\section{REFERÊNCIAS}

BENJAMIN, Walter. O narrador. Considerações sobre a obra de Nikolai Leskov. In: BENJAMIN, Walter. Magia e Técnica, Arte e Política: ensaios sobre literatura e história da cultura. Obras Escolhidas. vol. o1. São Paulo: Editora Brasiliense, 1985. p. 197-221.

FREIRE, Paulo. Ação cultural para a liberdade. 5. ed. Rio de Janeiro: Paz e Terra, 1981.

FREIRE, Paulo. Cartas à Guiné-Bissau: registros de uma experiência em processo. 2. ed. Rio de Janeiro: Paz e Terra, 1978.

11. BENJAMIN, 1985, p. 205. 
Paulo Freire: narrador e pensador

FREIRE, Paulo. Educação como prática da liberdade. Rio de Janeiro: Paz e Terra, 1967.

FREIRE, Paulo. Educação e atualidade brasileira. 1959. Tese de Concurso para a Cadeira de História e Educação - Escola de Belas Artes de Pernambuco, Recife, 1959.

FREIRE, Paulo. Extensão ou comunicação? Tradução de Rosisca Darcy de Oliveira. 7. ed. Rio de Janeiro: Paz e Terra, 1983.

FREIRE, Paulo. A importância do ato de ler: em três artigos que se completam. 26. ed. Prefácio de Antonio Joaquim Severino. São Paulo: Cortez/Autores Associados, 1982. (Coleção Polêmicas do nosso Tempo).

FREIRE, Paulo. Pedagogia da esperança: um reencontro com a pedagogia do oprimido. Rio de Janeiro: Paz e Terra, 1992.

FREIRE, Paulo. Pedagogia do oprimido. São Paulo: Paz e Terra, 1974.

FREIRE, Paulo. Trabalho, Comentário, Reflexão. Petrópolis/RJ: Editora Vozes, 1990.

VANNUCCHI, Aldo (Org.). Paulo Freire ao vivo. São Paulo: Loyola, 1983.

\section{SOBRE O AUTOR}

João Wanderley Geraldi. Professor do Departamento de Linguística e Diretor do Instituto de Estudos da Linguagem - UNICAMP.

E-mail: jwgeraldi@yahoo.com.br. 